\title{
COMBINAÇÃO DE MUITO COM SINTAGMAS NUS E DETERMINANTES: UMA CONTRIBUIÇÃO SEMÂNTICA AO PORTUGUÊS BRASILEIRO
}

\author{
Fernanda Bertolini* \\ Roberta Pires de Oliveira ${ }^{* *}$
}

\begin{abstract}
RESUM0: Este artigo apresenta os resultados obtidos por meio da aplicação de um teste de julgamento de gramaticalidade realizado para analisar as hipóteses levantadas por Pires de Oliveira e Souza (2018). 0 teste verificou a combinação de 'muito' com nomes masculinos e femininos encabeçados ou não por um artigo definido. Os resultados apontam que sentenças estruturadas pela combinação de 'muito' somado a sintagma nu feminino e 'muito' somado a sintagma determinante feminino são sentenças igualmente mal avaliadas pelos falantes de português brasileiro. Ao passo que, como previsto pelos autores, a combinação de 'muito' com um sintagma determinante masculino ou feminino é avaliada como marcada ou agramatical pelos participantes do teste. Entretanto, ao contrário da expectativa dos autores, a combinação de 'muito' com um sintagma nu feminino também teve avaliação negativa. Finalmente, como esperado, a combinação de 'muito' com um sintagma nu masculino é avaliada como uma sentença boa pelos falantes. Entendemos que a avaliação negativa de sentenças com determinante se deve a uma má formação semântica, ao passo que com o nu feminino a má formação é sintática.
\end{abstract}

PALAVRAS-CHAVE: Semântica; Experimentos; Gramaticalidade; Sintaxe.

\section{THE COMBINATION OF THE TERM MUITO WITH PURE AND DETERMINING SYNTAGMAS: A SEMANTIC CONTRIBUTION TO BRAZILIAN PORTUGUESE}

\begin{abstract}
Results obtained by applying tests for grammatical judgment to analyze hypothesis by Pires de Oliveira \& Souza (2018) are provided. The test investigated the combination of the term 'muito' with masculine and feminine nouns, with or without the definite article. Results show that sentences structured by the combination of 'muito' plus the pure feminine syntagma and 'muito' plus the feminine determining syntagma are sentences which are not properly evaluated by speakers of Brazilian Portuguese. On the other hand, the combination of 'muito' with the determining masculine or feminine syntagma is evaluated as non-marked or a-grammatical by participants. Against the authors' expectations, the combination of 'muito' with a pure feminine syntagma had a negative evaluation. As expected, the combination of 'muito' with the pure masculine syntagma was evaluated as good by speakers. The negative evaluation of sentences with determinants is due to inadequate semantic formation, whilst inadequate formation with the pure feminine is due to syntax.
\end{abstract}

KEYWORDS: Semantics; Experiments; Grammaticality; Syntax.

\footnotetext{
*Universidade Federal de Santa Catarina (UFSC), Brasil.

"Universidade Federal de Santa Catarina (UFSC), Brasil.
} 


\section{DISCUSSÃO TEÓRICA}

Este artigo apresenta os resultados preliminares de um teste de aceitabilidade realizado para verificar os julgamentos de gramaticalidade previstos por Pires de Oliveira e Souza (2018). ${ }^{3}$ Esse teste é a primeira etapa de uma pesquisa mais abrangente que inclui também uma tarefa de interpretação que está ainda em desenvolvimento. A intenção que subsidia o projeto é compreender a sintaxe e a semântica do 'muito' adverbial no português brasileiro (doravante, $\mathrm{PB}$ ), como exemplificado em (1): a. João dança muito; b. João compra muito.

A sentença em (1a) pode receber diferentes interpretações - muitas vezes, muito tempo e muito bem -, ao passo que a sentença em (1b) sugere a possibilidade de 'muito' ser um pronome indefinido, como propõe llari (1993). Neste caso, 'muito' indicaria muitas coisas. Nosso objetivo é compreender sua sintaxe e sua semântica. Neste projeto, investigamos as combinações com sintagmas nominais nus e com determinantes. Os sintagmas nus, como veremos, levantam um problema, pois, se considerarmos a literatura sobre eles (Müller, 2002), tais sintagmas deveriam se combinar com 0 'muito' adverbial; ao passo que os sintagmas definidos não se combinariam.

Embora aparentemente simples, a semântica de 'muito' levanta questões difíceis. 0 que conta como dançar muito depende do que é um dançar normal. Dançar muito é dançar acima do normal, de acordo com algum parâmetro dado, em geral, contextualmente. Assim sendo, estamos comparando o dançar do João a um padrão de dançar e afirmando que ele está acima da normalidade de dançar.

\footnotetext{
0 teste foi realizado na Universidade Federal de Santa Catarina (UFSC) e se constitui como parte de um projeto de extensão, cujo objetivo é desenvolver um material de apoio pedagógico a professores de língua portuguesa do ensino fundamental II e do ensino médio. Este projeto é financiado pela Fundação de Amparo à Pesquisa e Extensão Universitária (Fapeu) e foi aprovado pelo Comitê de Ética em Pesquisa da Universidade Federal de Santa Catarina (CEP-UFSC) - Número do projeto: 88571118.5.0000.0121.
}

A grande disputa sobre a semântica da comparação é se há ou não graus na ontologia. Klein (1980) defende que é possivivel entender a comparação, e, portanto, a semântica de 'muito', sem graus, ao passo que Kennedy (1997) afirma que graus são necessários. Neste artigo não iremos discutir essa questão. Assumimos, assim como Pires de Oliveira e Souza, que a semântica de 'muito' é a mesma para todos os domínios em que ele atua - nominal, adjetival e verbal - e que ele é um modificador de predicado. Nesse sentido, 'muito' designa a "extensão positiva da extensão positiva de um predicado" (PIRES DE OLIVEIRA; SOUZA, 2018, p. 223), seja esse predicado nominal, como em 'muito carro', adjetival, em 'muito alto', ou adverbial, como nos exemplos em (1).

Simplificando um pouco, a ideia é que um predicado como 'alto' reparte 0 domínio em: aqueles que são altos, aqueles que não são altos e aqueles que não são nem altos nem não altos, como na Figura 1, abaixo. 0 predicado 'alto' indica aqueles que estão na extensão positiva, ou seja, os que são altos. 'Muito' parte a extensão dos que são altos em muito altos e altos e denota aqueles que são muito altos, como na Figura 2:
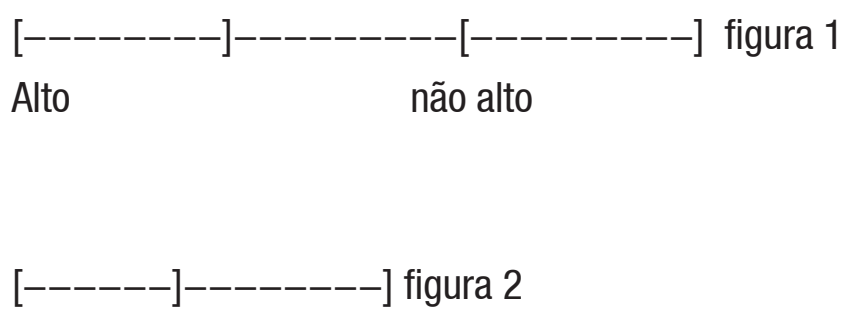

Muito alto alto

Embora haja muitas questões em aberto, nosso foco, nesta pesquisa, são as intuições de Pires de Oliveira e Souza. Os autores afirmam que 'muito' não é gramatical quando combinado com um sintagma encabeçado por um artigo definido, como ocorre nos exemplos em (2): 
(2) a. *João construiu muito a casa.

b. * João construiu muito o prédio.

Os autores argumentam que a agramaticalidade dessas sentenças se deve ao fato de que 'muito' necessita de pluralidade, já que estabelece uma comparação - comparar requer mais de um objeto, por isso (3) é agramatical:

(3) *João tem mais a casa que Maria.

Tanto em (3) quanto nas sentenças em (2), os sintagmas nominais denotam um único indivíduo. Há, assim sendo, uma coalizão: 'muito' solicita pluralidade e o sintagma definido denota um indivíduo único. Quando isso ocorre, de acordo com os autores, a única possibilidade de salvar a construção é "particionar" o objeto em vários pedaços, criando uma pluralidade. É por isso que as sentenças com sintagma determinante, se interpretadas, veiculam uma leitura partitiva.

Em (3), o João tem mais partes da casa do que a Maria. Do mesmo modo, os falantes julgam que as sentenças em (2) são inconsistentes e, por conta disso, recorrem à leitura partitiva: assim, se elas forem aceitas, são interpretadas como João construiu mais partes da casa do que é o normal ou mais partes do prédio, respectivamente. Nesse sentido, é como se tivéssemos 'João construiu muito (d)a casa' e 'João construiu muito (d)o prédio'.

Por outro lado, de acordo com Pires de Oliveira e Souza, sentenças com sintagmas singulares nus isto é, sintagmas que não são encabeçados por artigo definido e aparecem sem morfologia de plural, como exemplificado em (4) abaixo -, deveriam ser bem avaliadas gramaticalmente quando combinadas com 'muito', já que esse sintagma denota um ou mais de um indivíduo4:

(4) João comprou laranja na feira.
A sentença em (4) é verdadeira se João comprou uma ou mais de uma laranja. Logo, esse é um sintagma plural. Assim, as sentenças em (5) e (6), abaixo, deveriam ser gramaticais:

(5) \#João construiu muito casa.

(6) João construiu muito prédio.

No entanto, os autores afirmam que (5) é uma sentença marcada. Isto posto, o objetivo desta pesquisa é verificar se as intuições dos autores estão corretas e, em sequência, buscar uma explicação para essas observações.

Nossa hipótese é de que as sentenças em (2) são avaliadas como não aceitáveis, assim como a sentença em (5), mas por razões diferentes. Apenas a sentença em (6) é bem avaliada. Enquanto que as sentenças em (2) não são gramaticais porque há incompatibilidade semântica - 'muito' é plural enquanto que o sintagma definido é singular -, em (5) o problema é de ordem sintática.

Na próxima seção, apresentamos 0 teste de gramaticalidade e, em seguida, discutimos os resultados em busca de uma explicação para as ocorrências identificadas.

\section{JULGAMENTO DE GRAMATICALIDADE}

Realizamos um julgamento de gramaticalidade com falantes nativos de PB que procurou testar as hipóteses apresentadas. Trata-se de um teste offline, que não permite medir o processamento, mas verificar se dada sentença ou expressão pertence à gramática dos falantes.

Embora haja muitas críticas a essa metodologia atualmente, ela é ainda muito utilizada, em especial para verificar predições teóricas, como é o caso dessa nossa pesquisa.

\footnotetext{
${ }_{4}^{4}$ A literatura sobre 0 singular nu no PB é vasta. Ver, por exemplo, Ferreira (2017).
} 


\subsection{METODOLOGIA}

0 teste de julgamento de gramaticalidade foi executado em plataforma virtual e não houve controle no processo de sua realização. Cinquenta e três falantes nativos de PB responderam ao teste, que era composto por 32 sentenças (dispostas em 02 listas), das quais oito eram alvos, quatro eram controle e 20 eram sentenças distratoras.

Formulamos quatro sentenças controle, duas para cada lista do teste - uma positiva e outra negativa - com 0 intuito de controlar se o participante estava prestando atenção à tarefa. 0 falante que avaliou as duas sentenças controle diferentemente da avaliação esperada foi excluído do teste, já que havia grande chance de ele não estar prestando atenção à tarefa ou não estar engajado em respondê-la seriamente.

As sentenças distratoras, em contrapartida, foram elaboradas a fim de evitar que os participantes do teste tivessem consciência do que estava sendo testado; não havia, pois, nas sentenças distratoras, sintagmas com o objeto de estudo - 'muito' adverbial.

0 teste tinha como variáveis independentes 0 gênero do nome (masculino e feminino) e 0 artigo (presença e ausência). A variável dependente era 0 julgamento de aceitabilidade em escala Likertcomposta por sete pontos, dos quais 1 indicava 'sentença muito boa' e 7 'sentença completamente ruim'.

As sentenças-alvo que compuseram o teste estão dispostas a seguir:

1. 0 Daniel construiu muito (a) casa.

2. 0 Augusto construiu muito (o) prédio.

3. 0 professor corrigiu muito (a) prova.

4. 0 revisor corrigiu muito (0) erro.

5. 0 Murilo comprou muito (a) bebida.

6. A Marina comprou muito (0) cigarro.

7. A Letícia comeu muito (a) salsicha.

8. 0 Gabriel comeu muito (0) salgado.

\section{RESULTADOS E DISCUSSÃO}

Após a aplicação do teste, efetuamos uma análise dos dados obtidos por meio do Software RStudio, de modo a verificar as médias de aceitabilidade das sentenças obtidas com 0 julgamento de gramaticalidade dos participantes.

Além disso, construímos um modelo linear dos resultados (por meio do Linear Mixed Models) e verificamos que os dados analisados são significantes $(p=4.557 e-06)$. Verificou-se que sentenças com substantivo masculino no sintagma com determinante obtiveram média 4,99, isto é, foram avaliadas negativamente, já que a média na escala Likert era 3,5.

Por outro lado, sentenças com o substantivo masculino, porém nas quais não havia presença do artigo definido, obtiveram 3,65 , isto é, um valor próximo da média, o que pode indicar que os falantes não tinham certeza sobre a sentença ser ou não ser gramatical. As sentenças femininas definidas atingiram a média de 5,06 e, por fim, as sentenças com sintagma nu feminino obtiveram média de 5,55; nesse sentido, essas sentenças foram avaliadas negativamente.

Os dados analisados sugerem que as sentenças com sintagmas nus masculinos ('O Daniel construiu muito prédio') foram julgadas como mellhores, pelos falantes, quando em comparação às sentenças com sintagmas nus femininos (' 0 Daniel construiu muito casa') - neste caso, 0 valor de $p$ foi de $p=1.011 e-10$ - e, também, às sentenças com sintagmas definidos masculinos ('0 Daniel construiu muito o prédio'), com valor de $p$ igual a $p=4.421 \mathrm{e}-06$.

Não há diferença significativa entre sentenças com sintagmas definidos ou nus femininos; os dois tipos de sentenças foram avaliados como ruins. Além disso, as sentenças ' 0 Daniel construiu muito a casa' e 'O Augusto construiu muito o prédio' são marcadas ou agramaticais e, desse modo, comprova-se o que havia sido afirmado pelos autores em estudo. Entendemos que isso ocorra porque 'muito' exige pluralidade e 'a casa' e 'o prédio' denotam indivíduos singulares, como já mencionado na discussão inicial apresentada neste estudo. 
Em contrapartida, sentenças como '0 Daniel construiu muito casa', sobre a qual se esperava uma avaliação positiva - tendo em vista que 'muito' solicita pluralidade e, segundo a literatura, o sintagma nu, como em 'casa', é plural -, não foi bem avaliada. Por outro lado, '0 Augusto construiu muito prédio' é avaliada como sentença boa pelos falantes.

Concluímos, portanto, que as intuições dos autores que estamos estudando estão na direção correta. A explicação para a agramaticalidade de sentenças encabeçadas por artigo definido como, nos exemplos em (2), se deve a uma colisão entre a semântica de 'muito', que exige pluralidade, e a semântica do sintagma definido, que denota um único indivíduo em particular, logo, uma singularidade. Nossa expectativa é que se forçados a interpretar essas sentenças, os falantes irão particionar o objeto. Nosso próximo passo é investigar essa hipótese.

Já com relação às sentenças com os sintagmas nus, como exemplificados em (5) e (6), nossa hipótese é de que se trata de um bloqueio sintático. Em sentenças como (6), o sintagma não é interpretado como um sintagma nu, mas como um sintagma quantificado pela concordância, ou seja, a estrutura sintática atribuída pelos falantes é [ ${ }_{V P}$ construiu [ ${ }_{S N}$ muito prédio]] e não [ ${ }_{\mathrm{VP}}$ construiu muito ${ }_{S \mathrm{SN}}$ prédio]]. A interpretação como um sintagma quantificado está bloqueada para 0 nome feminino por causa da concordância.

Supondo que os falantes são guiados por um princípio de localidade - e, nesse sentido, assumindo a construção sintática como preferencialmente local sentenças como (5) serão consideradas agramaticais, visto que não há concordância em tais. Nossa hipótese é de que se houver deslocamento do sintagma nu como, no exemplo abaixo, a sentença será considerada gramatical:

(7) Casa, o João construiu muito.

Essa é, no entanto, uma tarefa a ser realizada posteriormente.

\section{CONSIDERAÇÕES FINAIS}

Nosso intuito nesta pesquisa foi verificar as intuições de Pires de Oliveira e Souza (2018) quanto às possibilidades de combinação do 'muito' adverbial.

Para tanto, construímos um teste de gramaticalidade que verificou como os falantes julgaram sentenças em que 'muito' se combina com sintagmas nus masculinos e femininos e sintagmas com determinante, também masculinos e femininos. 0s resultados suportam a intuição dos autores: sentenças com sintagmas definidos não são gramaticais; sentenças com sintagmas femininos nus também não são gramaticais e, por fim, sentenças com sintagmas masculinos nus são gramaticais.

A explicação para a incompatibilidade de 'muito' com sintagmas definidos se subsidia na semântica, já que 'muito' requer pluralidade e o sintagma definido denota uma singularidade. Em relação aos sintagmas nus, argumentamos que os participantes interpretaram 'muito prédio' como um sintagma quantificado; em 'muito casa', entretanto, essa interpretação é bloqueada, tendo em vista a ausência de concordância entre 'muito' e 'casa'. Sugerimos que esse é um bloqueio sintático, que ocorre por conta de uma condição de localidade, visto que 'muito' está próximo de 'casa'. Contudo, novos testes precisam ser realizados, em especial para verificar 0 contraste entre sentenças como 'O Augusto construiu muito casa' e 'Casa, o Augusto construiu muito'; se existir, de fato, influência da localidade, deverá ser possível identificar um contraste de aceitabilidade entre essas sentenças.

Os resultados apontam para a agramaticalidade de combinar 'muito' com sintagmas nominais, indicando que llari (1993) pode ter razão, no sentido de que se trata de um pronome indefinido e, portanto, não pode ser acompanhado por um nome, seja encabeçado por artigo seja nu. Uma outra hipótese é de que se trata efetivamente de um advérbio que modifica 0 verbo. Nesse caso, as leituras de quantidade que podemos ter com sentenças como (1b) seriam derivadas pragmaticamente de uma interpretação em que 'muito' quantifica eventos de compra. Para entendermos me- 
Ihor o que está ocorrendo precisamos, primeiro, verificar como os falantes interpretam sentenças como (1). Essa é a nossa próxima tarefa.

\section{REFERÊNCIAS}

FERREIRA, M. Bare Nominals in Brazilian Portuguese: an integral approach. John Benjamins Publishing, 2017. 322p.

KENNEDY, C. Projecting the adjective: the syntax and semantics of gradability and comparison. PhD Thesis, UCSD, 1997.

KLEIN, E. A Semantics for positive and comparative adjectives. Linguistics and Philosophy, v. 4, n. 1, p. 1-46, 1980.

MÜLLER, A. L. The Semantics of Generic Quantification in Brazilian Portuguese. PROBUS, v. 14, p. 279-298, 2002.

PIRES DE OLIVEIRA, R.; SOUZA, L. M. de. Um rascunho para a semântica de muito: explorando a semântica de delineação. Cadernos de Estudos Linguísticos, Campinas, v. 60, n. 1, p. 222-241, jan./abr. 2018.

RSTUDIO TEAM. RStudio: Integrated Development for R. RStudio, Inc., Boston, MA, 2015. Disponível em: <http://www.rstudio.com/>. Acesso em: 01 out. 2018.

Recebido em: 01/10/2018

Aceito em: 01/11/2018 